\title{
Artesunate Exerts a Direct Effect on Endothelial Cell Activation and NF- $\kappa$ B Translocation in a Mechanism Independent of Plasmodium Killing
}

\author{
Mariana C. Souza, ${ }^{1}$ Flávio Henrique Marcolino Paixão, ${ }^{1,2}$ Fausto K. Ferraris, ${ }^{1}$ \\ Isabela Ribeiro, ${ }^{3}$ and Maria das Graças M. O. Henriques ${ }^{1}$ \\ ${ }^{1}$ Laboratório de Farmacologia Aplicada, Departamento de Farmacologia Aplicada, Farmanguinhos, Fundação Oswaldo Cruz, \\ Rua Sizenando Nabuco 100, Manguinhos, 21041-250 Rio de Janeiro, RJ, Brazil \\ ${ }^{2}$ Laboratório de Educação Profissional em Técnicas Laboratoriais em Saúde, Escola Politécnica de Saúde Joaquim Venâncio, \\ Fundação Oswaldo Cruz, Rio de Janeiro, RJ, Brazil \\ ${ }^{3}$ Drugs for Neglected Diseases Initiative, Geneva, Switzerland \\ Correspondence should be addressed to Maria das Graças M. O. Henriques, gracahenriques@fiocruz.br
}

Received 30 May 2012; Revised 16 August 2012; Accepted 30 August 2012

Academic Editor: Mats Wahlgren

Copyright ( $) 2012$ Mariana C. Souza et al. This is an open access article distributed under the Creative Commons Attribution License, which permits unrestricted use, distribution, and reproduction in any medium, provided the original work is properly cited.

\begin{abstract}
Artemisinin and its derivates are an important class of antimalarial drug and are described to possess immunomodulatory activities. Few studies have addressed the effect of artesunate in the murine malaria model or its effect on host immune response during malaria infection. Herein, we study the effect of artesunate treatment and describe an auxiliary mechanism of artesunate in modulating the inflammatory response during experimental malaria infection in mice. Treatment with artesunate did not reduce significantly the parasitemia within $12 \mathrm{~h}$, however, reduced BBB breakdown and TNF- $\alpha$ mRNA expression in the brain tissue of artesunate-treated mice. Conversely, mefloquine treatment was not able to alter clinical features. Notably, artesunate pretreatment failed to modulate the expression of LFA-1 in splenocytes stimulated with parasitized red blood cells (pRBCs) in vitro; however, it abrogated the expression of ICAM-1 in pRBC-stimulated endothelial cells. Accordingly, a cytoadherence in vitro assay demonstrated that pRBCs did not adhere to artesunate-treated vascular endothelial cells. In addition, NF- $\kappa$ B nuclear translocation in endothelial cells stimulated with pRBCs was impaired by artesunate treatment. Our results suggest that artesunate is able to exert a protective effect against the $P$. berghei-induced inflammatory response by inhibiting NF- $\kappa \mathrm{B}$ nuclear translocation and the subsequent expression of ICAM-1.
\end{abstract}

\section{Introduction}

Artesunate is a semisynthetic derivative of artemisinin, the principal active component of a medicinal plant Artemisia annua which has been used as a remedy for fevers and chills for centuries in China [1]. Artemisinin and its derivatives are the most important class of antimalarial drug effective for both uncomplicated and severe malaria [2]. Besides, artemisinin and its derivates have been shown to possess anticancer [3], antiviral [4], and anti-inflammatory [5-8] activities. Artesunate has been reported to block the production of IL- $1 \beta$, IL- 6 and IL- 8 from TNF- $\alpha$-stimulated human rheumatoid arthritis fibroblast-like synoviocytes [9].
In addition, artesunate inhibits expression of toll-like receptor 4 induced by heat-killed E. coli lipopolysaccharide and production of TNF- $\alpha$, IL-6, and nitric oxide (NO). Further studies also demonstrated that artesunate protects septic mice challenged with $S$. aureus inhibiting TLR2 and Nod2 expression, and, consequently, decreasing TNF- $\alpha$ release [10] probably regulating the transcription factor $\mathrm{F}-\kappa \mathrm{B}$ activation. There are also some evidences that artesunate attenuates experimental allergic airway inflammation via negative regulation of PI3 K/Akt signaling pathway [11].

Murine cerebral malaria is a condition mainly attributed to parasite and leukocytes sequestration within the brain and the systemic inflammatory response to the infection 
$[12,13]$. Several experimental models of malaria have been adopted to understand the pathogenesis of the disease [13] as well as to discover new antimalarial drugs [14]. Among the experimental models, murine infection with $P$. berghei ANKA is the most commonly used animal model to study the mechanisms of cerebral malaria pathogenesis $[13,15]$. In this model, the neurological syndrome is associated with severe vasculopathy and systemic inflammatory response due to activation of leukocytes, cytokine production, and increased expression of endothelial adhesion molecules $[12,13,16,17]$.

Recently, the efficacy of antimalarial drugs in this experimental model was addressed, with findings showing that artemether and artesunate show the highest efficacies in rescuing mice with late-stage cerebral malaria [15]. The anti-malarial activity of artemisinin and its derivatives has been well demonstrated in vitro and in vivo $[18,19]$. Of note, the in vivo effect of artesunate on the host immune response during experimental malaria was never studied despite evidence demonstrating that this drug may present immunomodulatory activities $[10,11]$. Herein, we study the effect of artesunate on inflammatory markers during malaria infection and demonstrated that artesunate is able to exert a protective effect against the $P$. berghei-induced inflammatory response by inhibiting NF- $\kappa \mathrm{B}$ nuclear translocation and the subsequent expression of ICAM-1 in endothelial cells.

\section{Material and Methods}

2.1. Mice and the Model of Infection. C57BL/6 mice (18 to $20 \mathrm{~g}$ ) were provided by the Oswaldo Cruz Foundation breeding unit (Rio de Janeiro, Brazil) and caged with free access to food and fresh water in a room at the Farmanguinhos experimental facility with a temperature ranging from 22 to $24^{\circ} \mathrm{C}$ and a $12 \mathrm{~h}$ light/dark cycle until use. All experimental procedures were performed according to The Committee on Ethical Use of Laboratory Animals of Fundação Oswaldo Cruz.

For the Plasmodium berghei ANKA infection, mice were intraperitoneally (i.p.) inoculated with $10^{7}$ P. berghei pRBCs withdrawn from a previously infected mouse. Artesunate or mefloquine $(200 \mathrm{mg} / \mathrm{kg}$ diluted in $10 \%$ ethanol and 90\% propylene glycol, Farmanguinhos, Brazil) was orally administered by gavage (p.o.) (oral gavage needle, for mice, Thomas Scientific, USA) on the fifth day of infection. Mortality was checked daily. At the indicated time points after infection, a thick blood smear was performed for parasitemia determination by Diff-Quick staining. Finally, the mice were weighed and sacrificed in a $\mathrm{CO}_{2}$ chamber. Their lungs and spleens were excised and weighed, and the volume of these organs was evaluated by the organ/body weight ratio.

2.2. Evaluation of Blood-Brain Barrier Disruption. Bloodbrain barrier (BBB) disruption was evaluated as previously described [20] and modified by Pamplona et al. [21]. Briefly, mice received an intravenous (i.v.) injection of 1\% Evans blue (Sigma-Aldrich, São Paulo, Brazil) $12 \mathrm{~h}$ after artesunate administration on the fifth day of $P$. berghei infection. Mice were sacrificed $1 \mathrm{~h}$ later, and their brains were weighed and placed in formamide $\left(2 \mathrm{~mL}, 37^{\circ} \mathrm{C}, 48 \mathrm{~h}\right)$ to extract the Evans blue dye from the brain tissue. Absorbance was measured at $620 \mathrm{~nm}$ (SpectraMax 190, Molecular Devices, California, USA). The concentration of Evans blue was calculated using a standard curve. The data are expressed as mg of Evans blue per $g$ of brain tissue.

2.3. Histological Study. Brains were fixed and embedded in paraffin and from each $80 \mu \mathrm{m}$ of tissue, $4 \mu \mathrm{m}$ thin sections were obtained and stained with Hematoxylin-Eosin (Merck, Rio de Janeiro, Brazil). Congested capillaries from the superficial cerebral cortex were quantified under an optical microscope $(\times 1000$ magnification), and the percentage of congested microvessels was obtained by counting 100 vessels from each brain slide.

2.4. TNF- $\alpha$ mRNA Expression by RT-PCR. Total RNA from the brains of uninfected, $P$. berghei-infected and artesunatetreated $P$. berghei-infected mice (single dose, treated $12 \mathrm{~h}$ before on the fifth day of infection) was collected using TRIzol Reagent (Invitrogen, São Paulo, Brazil). After DNase treatment (RQ1 RNase-Free DNase), the mRNA was reverse transcribed using Moloney murine leukemia virus (MMLV) reverse transcriptase and an oligo(dT) 15 primer. The following primers were used to amplify TNF- $\alpha$ cDNA: sense, $5^{\prime}$-GATCTCAAAGACAACCAACATGTG-3', and antisense, $5^{\prime}$-CTCCAGCTGGAAGACTCCTCCCAG-3'. PCR was performed using the following parameters: 1 cycle of $95^{\circ} \mathrm{C}$ for $90 \mathrm{sec}$ and 27 cycles of denaturation at $95^{\circ} \mathrm{C}$ for $30 \mathrm{sec}$, annealing at $45^{\circ} \mathrm{C}$ for $1 \mathrm{~min}$, and elongation at $72^{\circ} \mathrm{C}$ for $26 \mathrm{sec}$. $\beta$-Actin primers were used to validate the integrity of the cDNA in each reaction. PCR products were separated by $2 \%$ agarose gel electrophoresis and visualized by UV exposure on a transilluminator. The PCR products were obtained using a GeneAmp PCR System 2400 (Perkin Elmer, Massachusetts, USA). The value corresponding to the TNF$\alpha$ mRNA expression was measured using the $\beta$-actin mRNA levels as a reference.

2.5. Murine Endotoxic Shock. Murine endotoxic shock was induced by intraperitoneal injection of lipopolysaccharides (LPS; $25 \mu \mathrm{g} /$ mouse) and D-galactosamine (20 mg/mouse) diluted in PBS $(200 \mu \mathrm{L})$ in previously artesunate-treated mice $(100 \mathrm{mg} / \mathrm{Kg}$, p.o., $1 \mathrm{~h}$ before). Three hours after endotoxic shock induction, mice were euthanized and blood was recovered for TNF- $\alpha$ evaluation. The plasma TNF- $\alpha$ protein levels were assayed by a standard sandwich ELISA in accordance with the manufacturer's instructions ( $\&$ \&D Systems, Minneapolis, USA).

2.6. Immunofluorescent Staining and Flow Cytometric Analysis. Splenocytes from normal C57BL/6 mice were isolated by Histopaque-1077 (Sigma-Aldrich) and treated with artesunate $(300 \mathrm{ng} / \mathrm{mL})$. One hour after treatment, the cells were washed, incubated with normal red blood cells (RBCs) or parasitized red blood cells (pRBCs), and maintained at $37^{\circ} \mathrm{C}$ in $5 \% \mathrm{CO}_{2}$ for $4 \mathrm{~h}$. The RBCs and pRBCs were then lysed, and the splenocytes were washed prior to 
immunofluorescent staining. The cells were then incubated in PBS plus $10 \%$ rat serum and $0.1 \%$ sodium azide (PBS-S, Sigma-Aldrich) and blocked with Fc $\gamma$ IIR monoclonal antibodies (mAb; 1:100, CD16/CD32, BD Pharmingen, California, USA) for $30 \mathrm{~min}$ at $4^{\circ} \mathrm{C}$. After blocking, the cells were labeled with purified $\mathrm{mAb}$ anti-mouse lymphocyte function-associated antigen (LFA)-1 followed by staining with secondary FITC-conjugated anti-rabbit IgG (SigmaAldrich) antibodies diluted in PBS-S and incubated for another $30 \mathrm{~min}$ at $4{ }^{\circ} \mathrm{C}$. The cells were then washed and resuspended in $\mathrm{PBS} / 0.1 \%$ sodium azide for data acquisition in a FACS calibur flow cytometer (BD Biosciences, California, USA). Forward scatter (FSC) and side scatter (SSC) were set to exclude dead cells, and at least $10^{4}$ lymphocytes were analyzed per sample. Control staining to determine the positive population was performed based on an irrelevant IgG isotype labeled with FITC. Once determined, the quadrants were rigorously maintained for all analyses. Data analysis was performed using CellQuest software (BD Immunocytometry Systems, California, USA).

2.7. Cytoadherence Assay. The murine vascular endothelial cell line tEnd. 1 was cultured in RPMI 1640 medium supplemented with $10 \%$ heat-inactivated fetal bovine serum (FBS), $2 \mathrm{mM}$ L-glutamine, $100 \mathrm{IU} / \mathrm{mL}$ penicillin, and $100 \mu \mathrm{g} / \mathrm{mL}$ streptomycin at $37^{\circ} \mathrm{C}$ in a humidified atmosphere containing $5 \% \mathrm{CO}_{2}$. For the infected erythrocyte adhesion assay, tEnd.1 cells were plated in 24-well culture chambers (Nunc, New York, USA) ( $10^{5}$ cells/well) and cultured for $24 \mathrm{~h}$. Before each experiment, the tEnd.1 cells were treated with $\operatorname{IgG}(20 \mu \mathrm{g} / \mathrm{mL})$, anti-mouse ICAM-1 $(20 \mu \mathrm{g} / \mathrm{mL})$ or artesunate $(300 \mathrm{ng} / \mathrm{mL})$. One hour after treatment, the cells were washed, and RBCs or pRBCs were then allowed to adhere to the tEnd. 1 cultures (50 erythrocytes/tEnd.1, 60\% parasitemia) for $1 \mathrm{~h}$. Nonadherent erythrocytes were gently washed away with PBS, and the remaining cells were subsequently fixed in ethanol and stained with Giemsa (Merck). The number of adhered erythrocytes per tEnd.1 cell was determined by direct counting. The data are expressed as an association index calculated as previously described [22]: Adhesion Index $(\mathrm{AI})=\{[($ tEnd. 1 with bound erythrocytes $) /$ total tEnd.1 number $] \times[$ (erythrocytes bound to tEnd.1)/total tEnd.1 number] $\} \times 100$. The adhesion of erythrocytes was also measured essentially as previously described [23]. The erythrocytes were washed with sterile PBS and incubated with $50 \mu \mathrm{M}$ CFSE (Invitrogen) for $30 \mathrm{~min}$ at $4^{\circ} \mathrm{C}$. Cells were then washed, resuspended in sterile saline, and allowed to adhere for $1 \mathrm{~h}$, and nonadherent erythrocytes were gently washed away with PBS as described above. The fluorescences corresponding to remaining cells were read in SpectraMax M5 Microplate Reader (Molecular Devices), and the results expressed as mean of fluorescence per well.

2.8. Immunocytochemistry. Cell pretreatment and stimulation were performed as described above. Immunofluorescent studies were performed as described previously [24]. To evaluate NF- $\kappa \mathrm{B}$ translocation, cells were permeabilized with 0.1\% Triton X-100 (Amersham Biosciences) after fixation with $4 \%(\mathrm{w} / \mathrm{v})$ paraformaldehyde and $4 \%(\mathrm{w} / \mathrm{v})$ sucrose followed by blocking with $2 \%$ bovine serum albumin. The cells were then incubated with anti-p65 (nuclear factor kappalight-chain-enhancer of activated B cells) NF- $\kappa$ B (1:50, Santa Cruz Biotechnology) or anti-intercellular adhesion molecule (ICAM-1; $1: 100$, BD Pharmingen) mAb and subsequently incubated with the appropriate secondary FITCconjugated antibody (Santa Cruz Biotechnology). Microscopic analysis of the fluorescent images was performed using a laser scanning confocal microscope software (Fluoview FV300 3.3 Olympus). The nuclear translocation of NF$\kappa \mathrm{B}$ was measured by immunofluorescence in nucleus using Image-Pro Plus Software (Media Cybernetic).

2.9. Statistical Analysis. Experiments in which three or more groups were compared statistical significance was assessed using ANOVA followed by the Newman Keuls $t$-test. Experiments in which two groups were compared statistical significance was assessed using $t$-test. The results are expressed as the mean \pm SEM and the significance level in all cases was set at $P<0.05$. In order to compare the percentage of survival, it was used the log-rank (Mantel-Cox) test and the significance level was set at $P<0.05$.

\section{Results}

3.1. Evaluation of Different Aspects of Severe Malaria after Single-Dose Administration of Artesunate $5 d$ after P. berghei Infection. Mice developed symptoms of cerebral malaria, since altered neurological functions as reflex and sensory function, motor behaviour, autonomous function, and muscle tone and strength were observed on days 5-6 after $P$. berghei ANKA infection. The infected mice also exhibited elevated parasitemia and a high mortality rate (Figures $1(\mathrm{a})$ and $1(\mathrm{c}))$. Treatment with artesunate on the fifth day after infection improved the clinical outcome and prolonged survival up to $100 \%$ within $12 \mathrm{~h}$ of treatment $(P=0.0158$; Figure 1(c)). Interestingly, at 12 hours after treatment the decrease in parasitemia was less than $30 \%$. Notably, treatment with mefloquine did not prevent $P$. berghei infectioninduced death $(P=0.212$; Figure $1(\mathrm{~b}))$ although reduced the same ratio of parasitemia as observed with artesunate treatment (25\%).

We also observed that $P$. berghei-infected mice had an increased accumulation of Evan's blue in their brains, suggesting BBB disruption (Figure 1(f)). In addition, infected mice had an increased body/lung weight ratio and body/ spleen weight ratio when compared with uninfected mice (Figures 1(d) and 1(e)). Interestingly, although the single treatment of artesunate only caused a slight reduction in the body/spleen weight ratio, it led to a significant inhibition in the body/lung and dramatically decreased the accumulation of Evan's blue in the brain within $12 \mathrm{~h}$ (Figure 1(f)). It is important to note that in spite of parasitemia inhibition, treatment with mefloquine was not able to reduce either lung or spleen/body weight ratios and did not impair Evan's blue extravasations to brain tissue (Figures $1(\mathrm{~d})-1(\mathrm{f})$ ). 

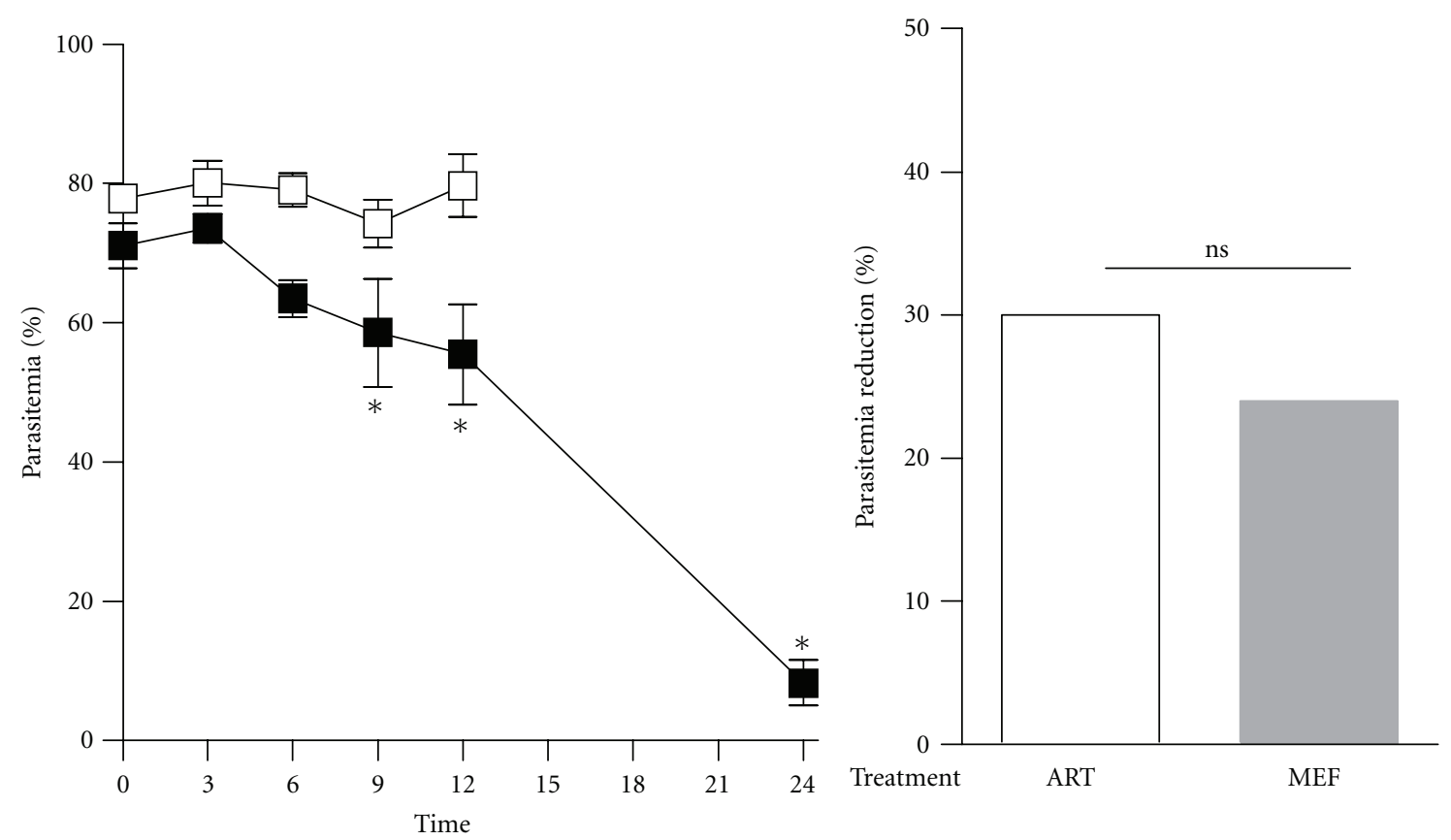

(hours after artesunate treatment)

$-\square-$ Vehicle

$-\square$ Artesunate $200 \mathrm{mg} / \mathrm{kg}$

(a)

(b)
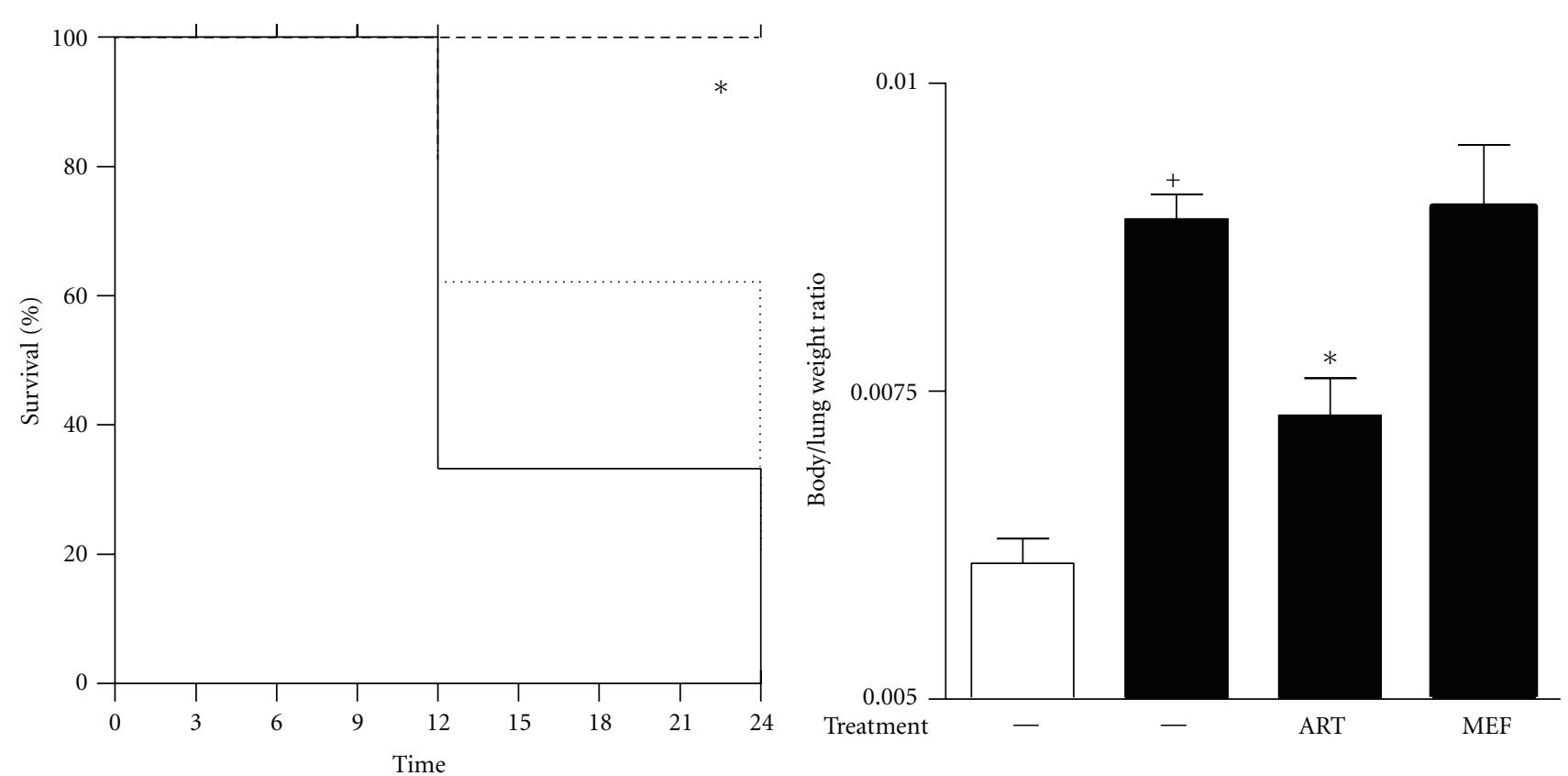

(hours after artesunate treatment)

$\perp$ Vehicle
$-\perp-$ Artesunate
..... Mefloquine

(c)

(d)

Figure 1: Continued. 


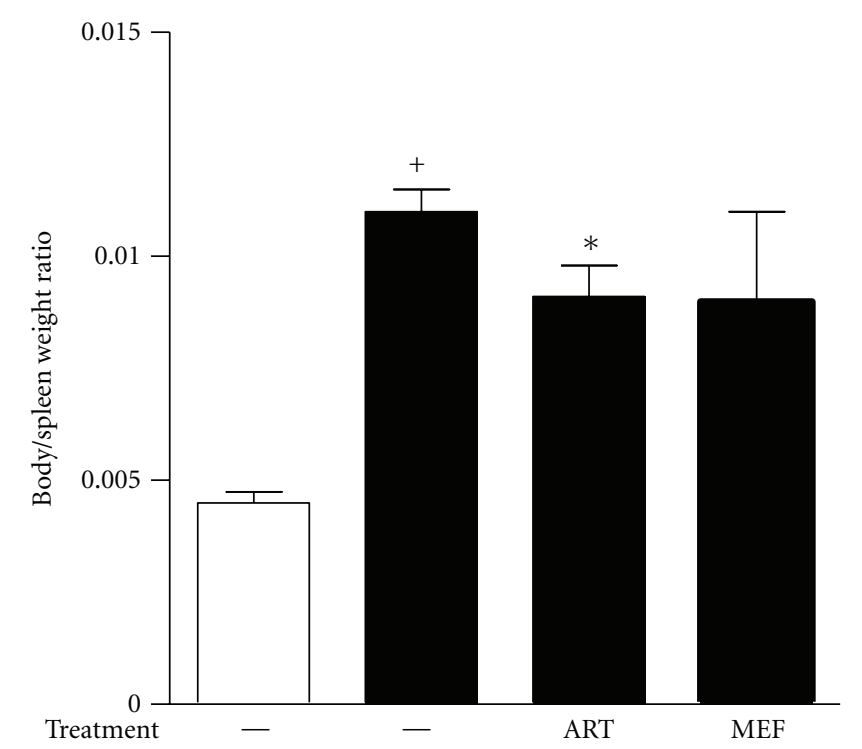

(e)

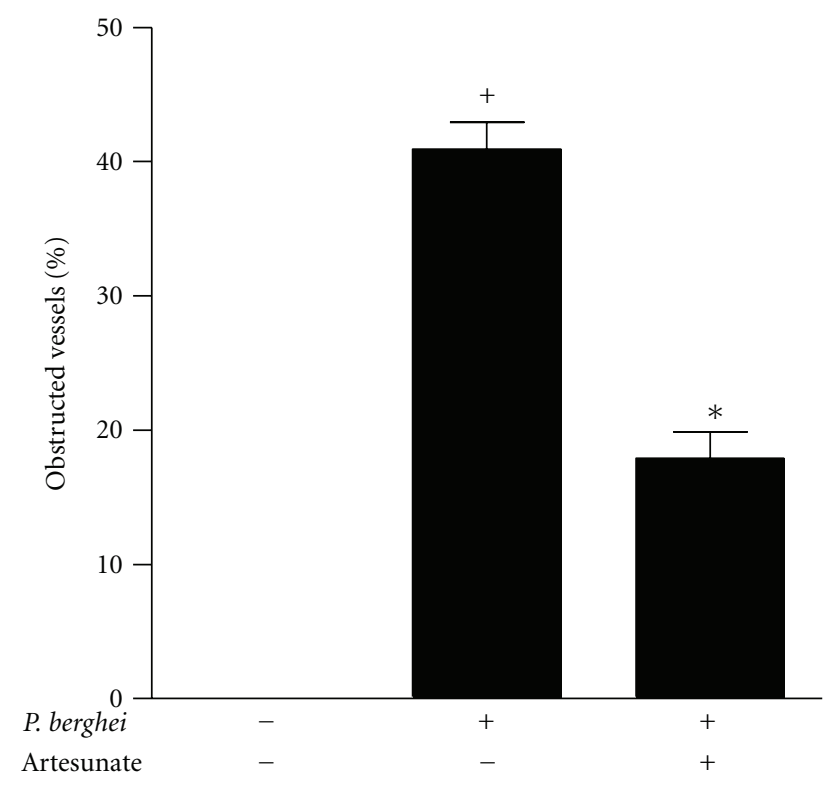

$(\mathrm{g})$

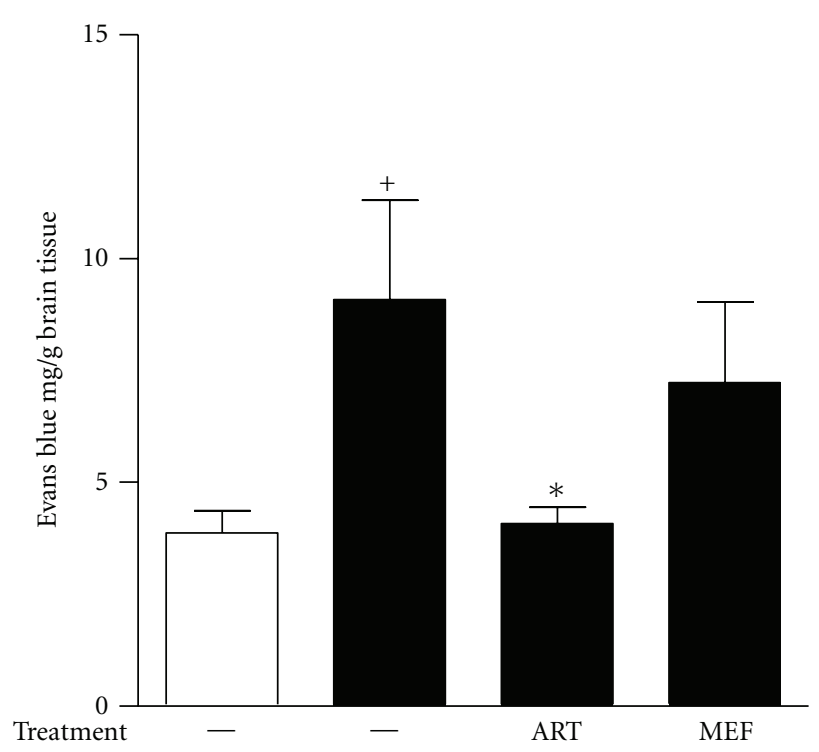

(f)

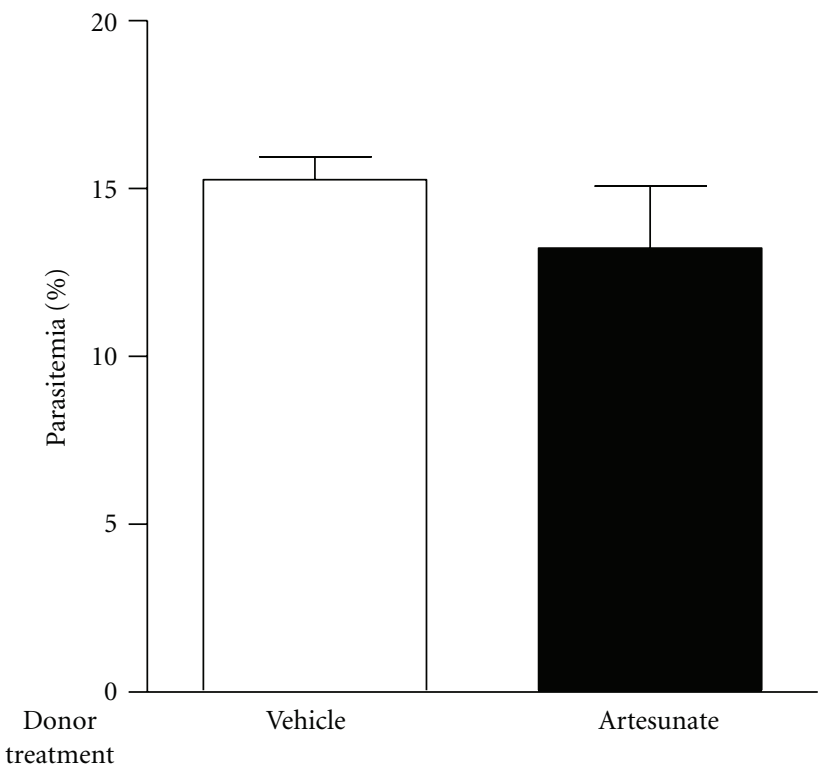

(h)

Figure 1: (a) Parasitemia was analyzed in a blood smear from each mouse. (b) Artesunate (200 mg/Kg; open bars) and mefloquine $(200 \mathrm{mg} / \mathrm{Kg}$; gray bars) antimalarial activity after administration on the fifth day of infection. (c) The survival of mice-treated artesunate (- - , $200 \mathrm{mg} / \mathrm{Kg})$, mefloquine (.., $200 \mathrm{mg} / \mathrm{Kg}$ ), or vehicle (-) was administered on the fifth day of infection. (d) Body/lung weight ratio, (e) body/spleen weight ratio, and (f) BBB disruption of uninfected (open bars), infected (closed bars), or infected mice that received a single dose of artesunate $(200 \mathrm{mg} / \mathrm{Kg})$ on the fifth day of infection. BBB disruption was assessed using Evans blue. The dye quantification is shown as the mean mg of Evans blue per $\mathrm{g}$ of brain tissue. (g) Microvascular congestion was assessed by H\&E staining of brain sections on the fifth day of infection. (h) Evaluation of infection rate of erythrocytes transferred from nontreated P. berghei-infected mice (open bars) or from artesunate-treated $P$. berghei-infected mice (closed bars). The results are expressed as the mean \pm SEM from six animals/per group of three experiments. Statistically significant differences $(P<0.05)$ between the control and $P$. berghei-infected groups are indicated by + , and significant differences $(P<0.05)$ between the untreated and artesunate-treated infected mouse groups are indicated by $*$.

We further analyzed sections from brains taken from uninfected, $P$. berghei-infected, and $P$. berghei-infected, mice treated $12 \mathrm{~h}$ before with artesunate. As expected, abnormal features were observed in the brain sections from infected mice, that is, capillary congestion caused by the presence of leukocytes adhered to the endothelial cells occasionally occluding the vessel lumens, suggesting cellular activation. In accordance to the findings of Clemmer et al. [15], brain sections from infected mice that were treated with artesunate, showed a reduction in the numbers of congested capillaries, 

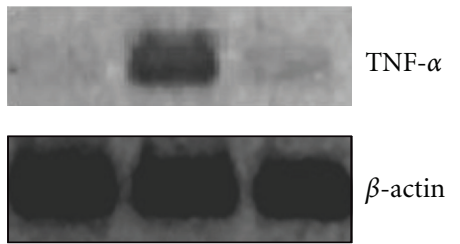

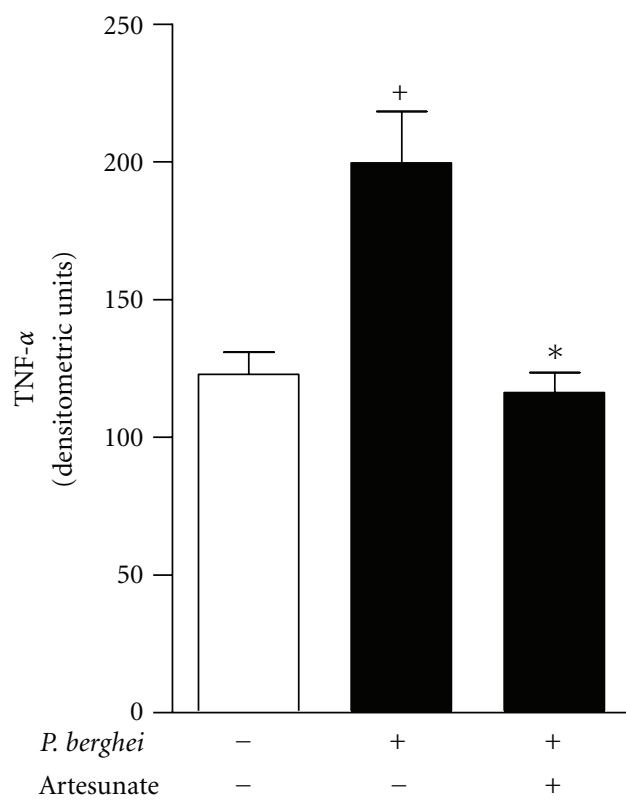

(a)

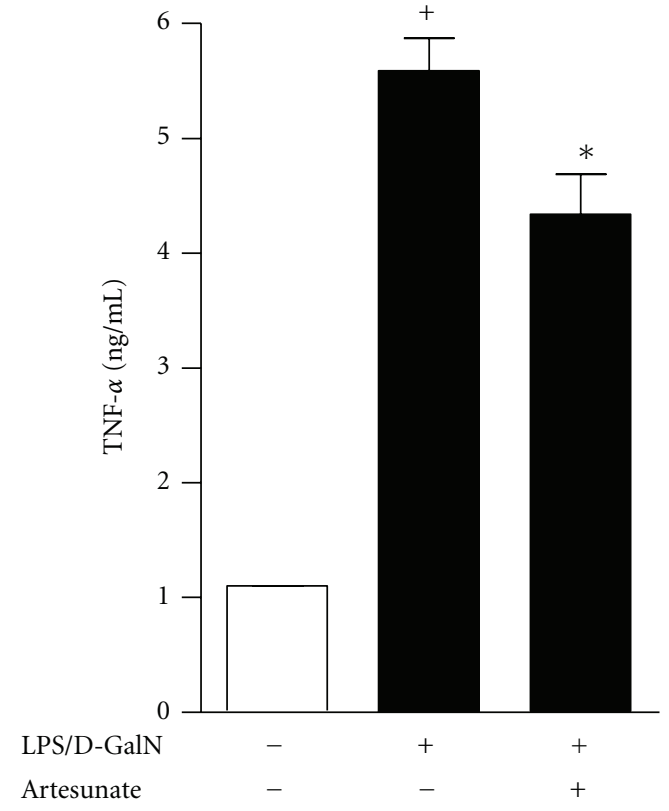

(b)

FIGURE 2: (a) TNF- $\alpha$ mRNA expression in the brains of uninfected (open bars), infected (closed bars), or infected mice that received a single dose of artesunate $(200 \mathrm{mg} / \mathrm{Kg}$ ) on the fifth day of infection. (b) Inhibition of TNF- $\alpha$ production during murine endotoxic shock after treatment with artesunate. The results are expressed as the mean \pm SEM from three animals per group of three experiments. Statistically significant differences $(P<0.05)$ between the control and $P$. berghei-infected groups are indicated by + , and significant differences $(P<0.05)$ between the untreated and artesunate-treated infected mouse groups are indicated by $*$.

endothelial cell thickness, and leukocyte detachment from the vessel walls, suggesting a putative effect of artesunate in cell adherence.

To roll out that artesunate effect was not due to killing of parasites, erythrocytes from donor nontreated mice or from mice treated with artesunate $12 \mathrm{~h}$ before were transplanted into uninfected mice. This resulted in a similar infection rate (Figure $1(\mathrm{~h})$ ) showing the presence of live parasites after treatment with artesunate under these specific experimental conditions.

3.2. Production of TNF- $\alpha$ after Artesunate Treatment. Because artesunate caused a reduction of endothelial cell thickness and the detachment of leukocytes from the brain vasculature during experimental severe malaria, we investigated the mechanism by which artesunate affected endothelial cell activation. The expression of TNF- $\alpha$, a well-described endothelial cell activator [25], was investigated first in a qualitative PCR assay. As expected, TNF- $\alpha$ mRNA expression was increased in the brain tissue of $P$. berghei-infected mice, whereas TNF- $\alpha$ expression was decreased in the brain tissue of artesunate-treated infected mice (Figure 2(a)). We further observed that artesunate treatment was also able to reduce systemic TNF- $\alpha$ production, by means of ELISA assay, in a murine endotoxic shock model (Figure 2(b)) suggesting that artesunate could exhibit activity in the systemic inflammatory response in vivo.

3.3. LFA-1 Expression in Splenocytes Stimulated In Vitro by P. berghei-Infected Erythrocytes. To assess whether artesunate treatment could modulate the attachment of leukocytes to endothelium we first addressed the effect of artesunate in the expression the integrin CD11a/CD18 (also known as LFA1; Lymphocyte function-associated antigen 1), the adhesion molecule described as responsible for the attachment of leukocytes in cerebral malaria. The expression of LFA-1 was measured in naive splenocytes stimulated with pRBCs in vitro. Stimulation with pRBCs leads to an increased expression of LFA-1 on the cell membrane of splenocytes when compared with cells stimulated with RBCs. Interestingly, pretreatment with artesunate $(300 \mathrm{ng} / \mathrm{mL})$ does not modulate the expression of LFA-1 in pRBC-stimulated splenocytes (Figure 3). 

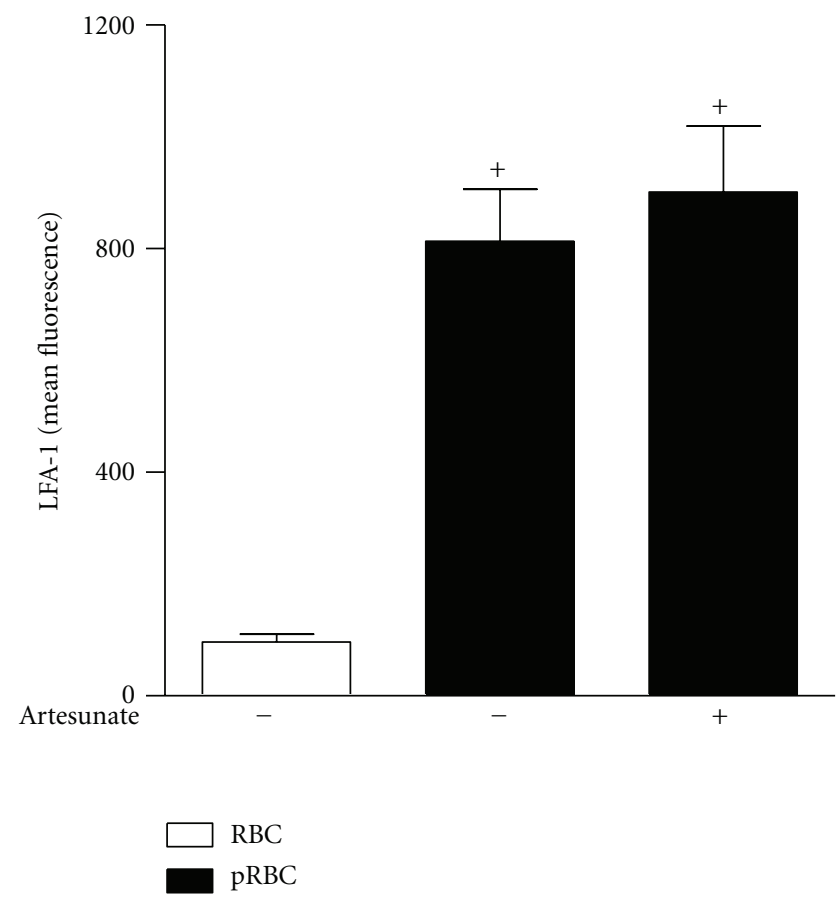

(a)

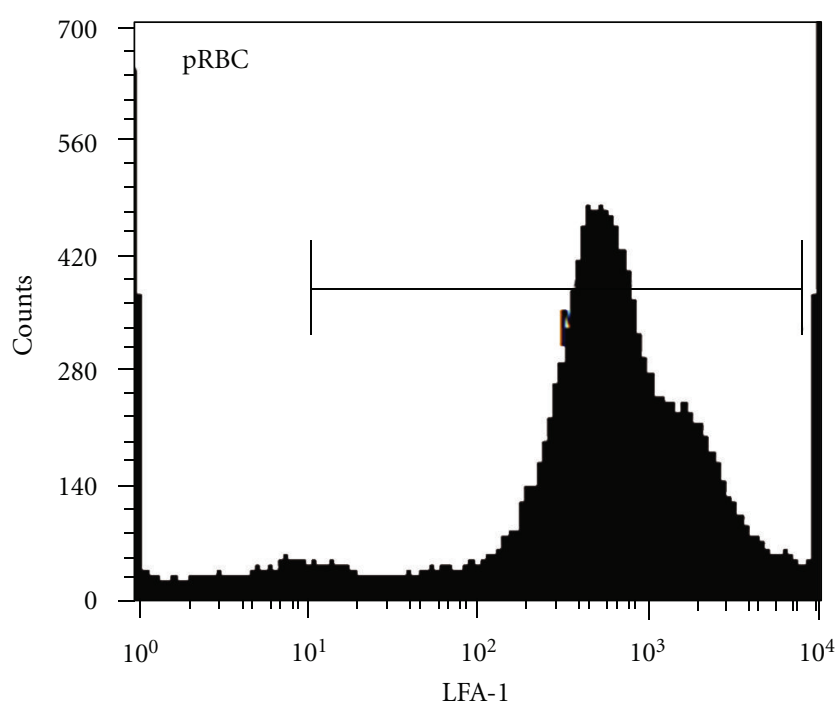

(c)

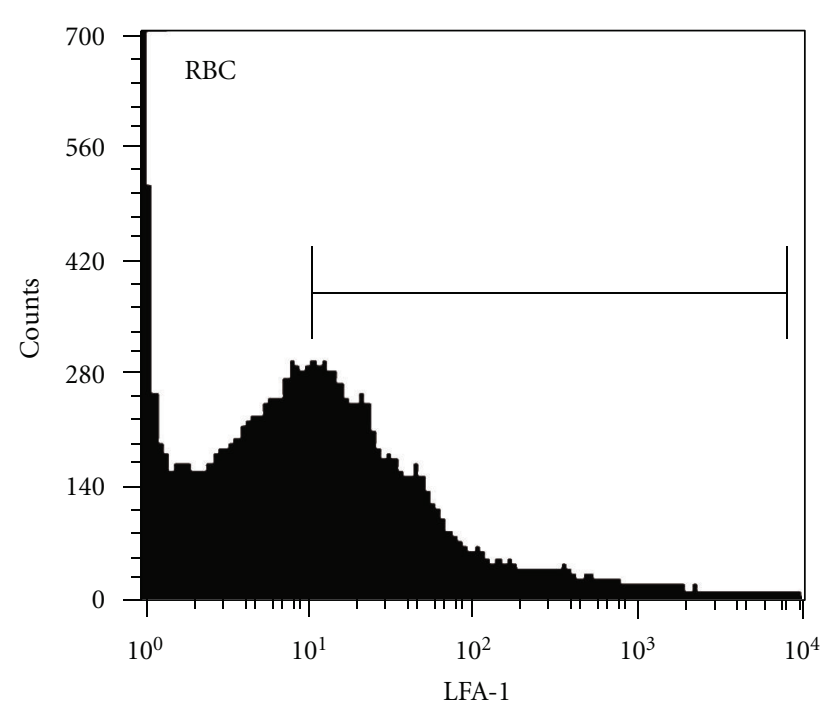

(b)

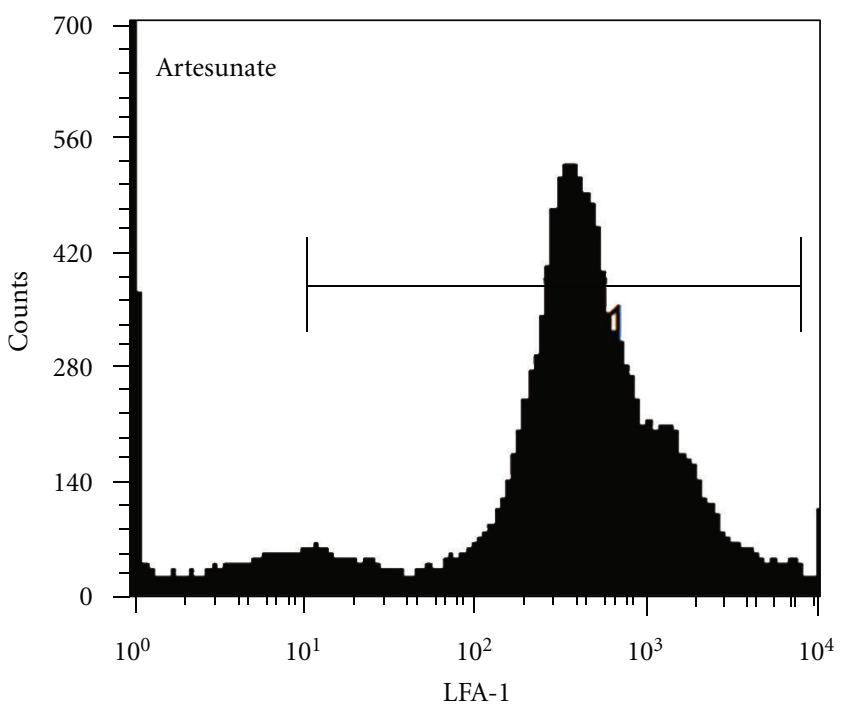

(d)

FIGURE 3: LFA-1 expression by splenocytes treated with artesunate and activated by pRBC. Representative histograms demonstrate the increase in fluorescence indicated by increase in LFA-1 expression in splenocytes. The results are expressed as the mean \pm SEM from at least six animals per group from two different experiments. Statistically significant differences $(P<0.05)$ between the control and $P$. bergheiinfected groups are indicated by + .

3.4. ICAM-1 Expression and $p R B C$ Adhesion to Endothelial Cells. We next investigated the effect of artesunate in the ligant of LFA-1, the intracellular adhesion molecule-1 (ICAM1). The coculture of pRBCs and endothelial cells leads to an increase of ICAM-1 expression in endothelial cells, whereas RBC stimulation did not. We observed that pretreatment with artesunate $(300 \mathrm{ng} / \mathrm{mL})$ inhibited the expression of ICAM-1 in these cells (Figure 4(a)). Interestingly, blockade of ICAM-1 inhibit pRBC adhesion to endothelial cells $(P=0.0007$; Figure $4(\mathrm{~b}))$. In agreement with these findings, pRBCs were able to adhere to endothelial cells and the treatment of tEnd. 1 cells with artesunate $(300 \mathrm{ng} / \mathrm{mL})$ was able to inhibit pRBC adhesion (Figure $4(\mathrm{c})$ ). We further studied the spontaneous adhesion of RBC to TNF- $\alpha$-activated 


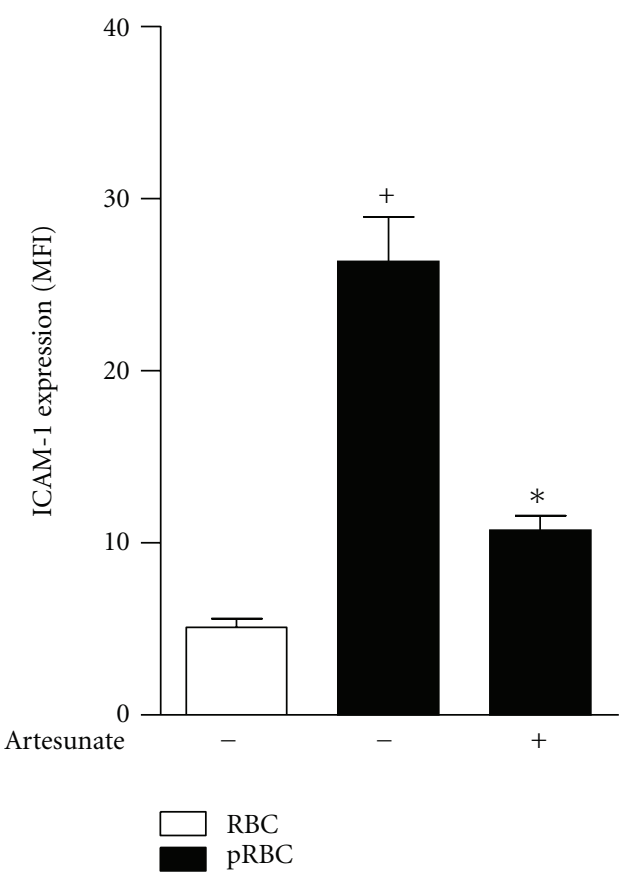

(a)

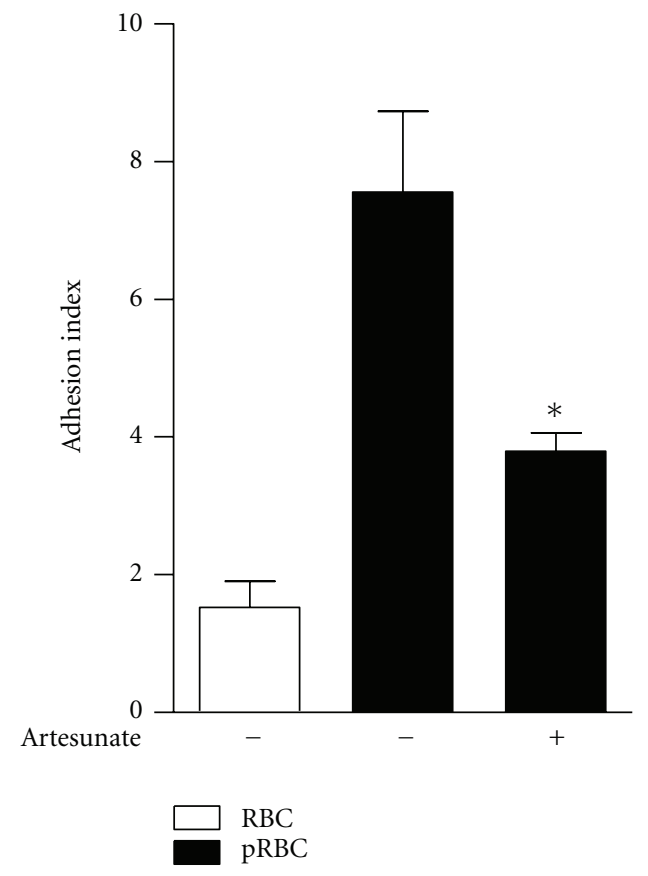

(c)

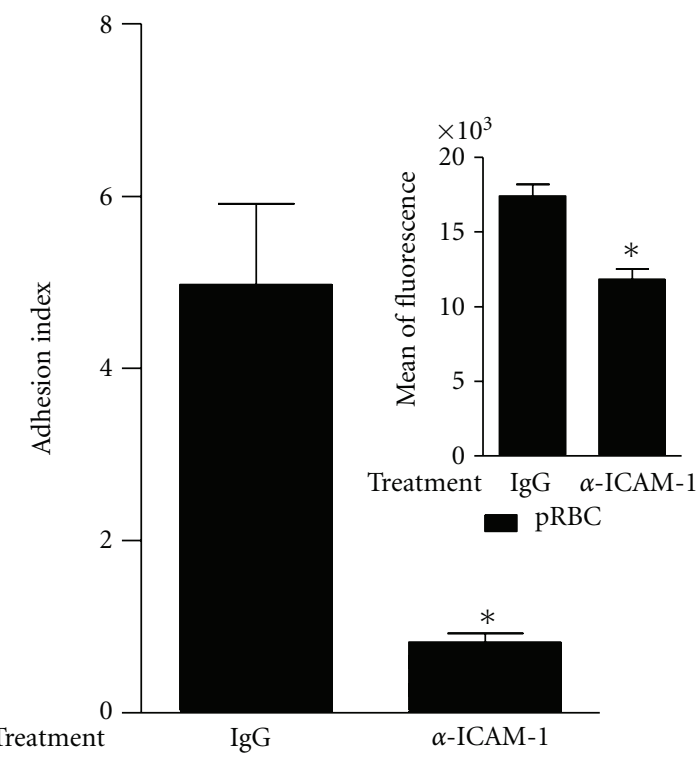

pRBC

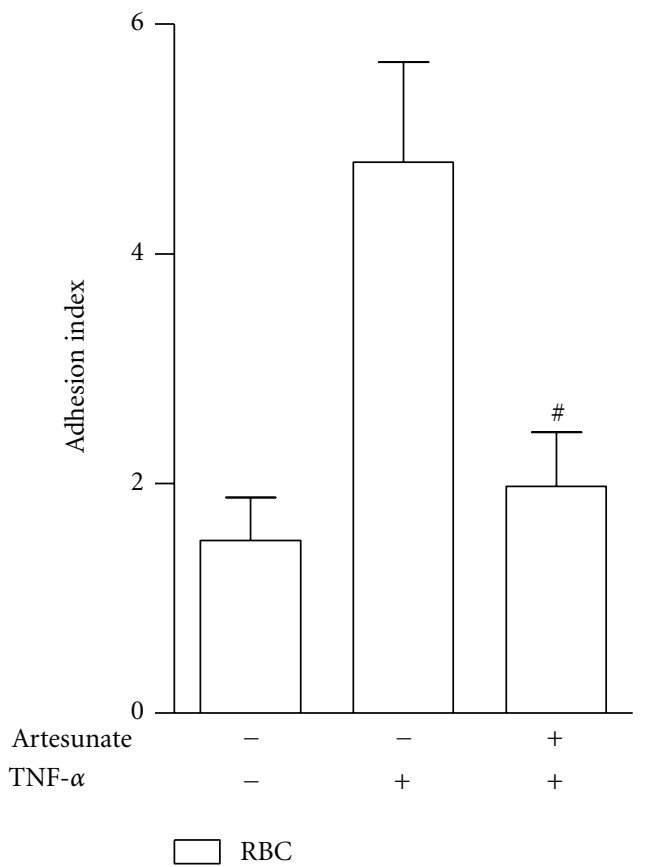

(d)

FIGURE 4: ICAM-1 expression and cytoadhesion of pRBC in the t.End.1 vascular endothelial cell line. (a) ICAM-1 expression was evaluated in t.End.1 vascular endothelial cells pretreated with artesunate $(300 \mathrm{ng} / \mathrm{mL})$ and stimulated with RBCs or pRBCs. (b) Endothelial cells were pretreated with IgG or anti-mouse ICAM-1 $(20 \mu \mathrm{g} / \mathrm{mL})$ and incubated with pRBCs. The adhesion of pRBC was calculated by the adhesion index or by fluorescence (insert) as described in the Material and Methods. (c-d) Endothelial cells were pretreated or not with artesunate $(300 \mathrm{ng} / \mathrm{mL})$, followed by incubation with RBCs (c) or pRBCs (d) for $1 \mathrm{~h}$. The results are expressed as the mean \pm SEM from three different experiments. Statistically significant differences $(P<0.05)$ between the RBC and pRBC groups are indicated by + , significant differences between pRBCs and pRBCs cultured with t.End.1 pretreated with artesunate are indicated by $*$, and significant differences between RBCs and RBCs cultured with t.End.1 pretreated with artesunate are indicated by \#. 


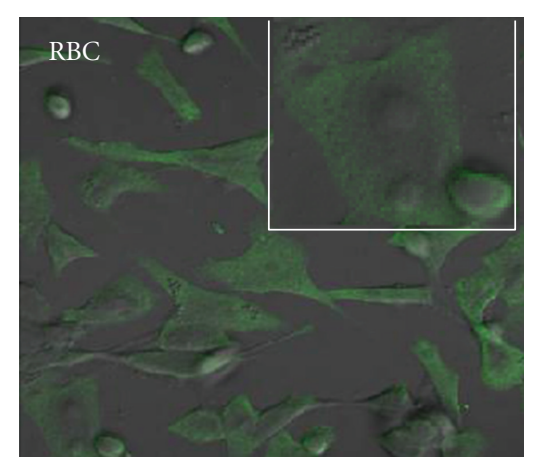

(a)

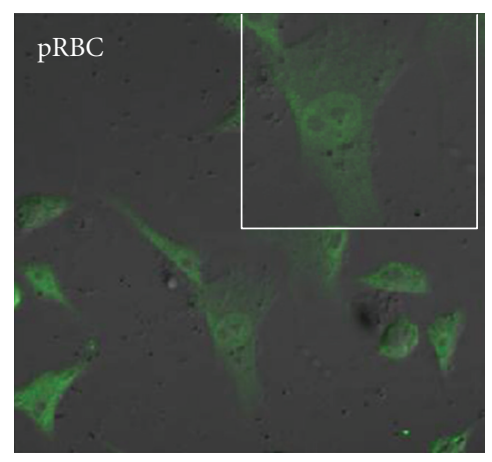

(b)

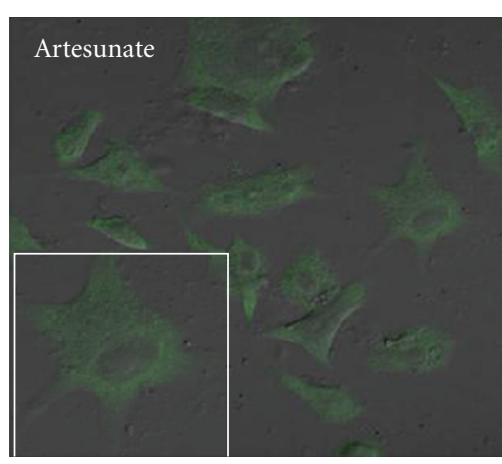

(c)

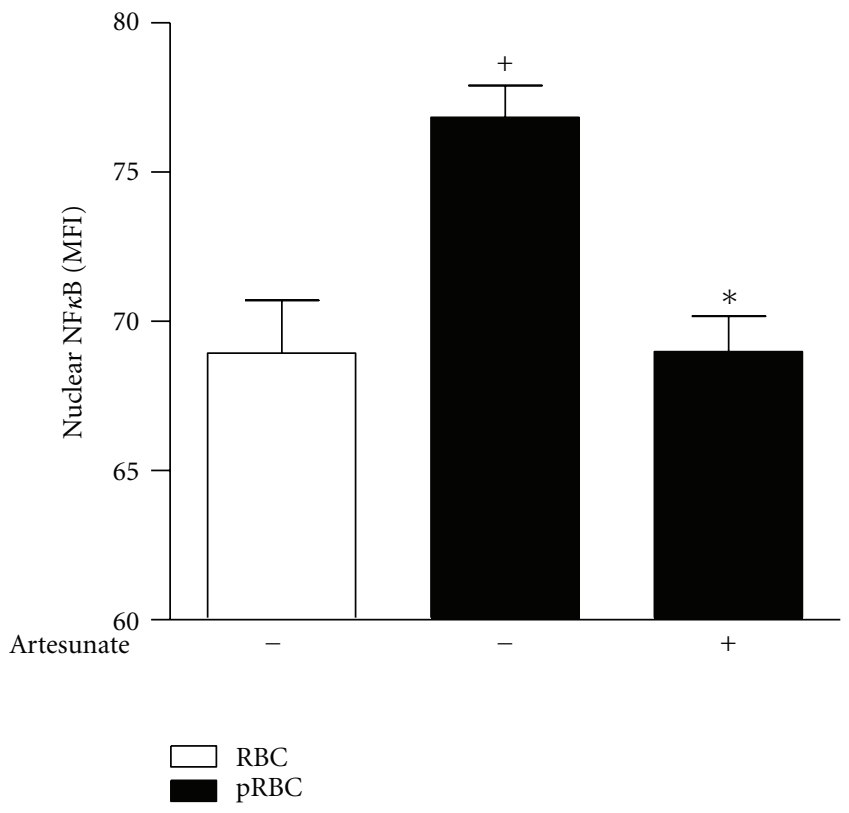

(d)

FIGURE 5: NF- $\kappa$ B translocation into the nucleus of pRBC-stimulated t.End.1 vascular endothelial cells. t.End.1 cells were pretreated or not with artesunate $(300 \mathrm{ng} / \mathrm{mL})$ and stimulated with RBCs or pRBCs as described in the Material and Methods section. Translocation of p65 $\mathrm{NF}-\kappa \mathrm{B}$ was observed by laser scanning confocal microscopy and measured as fluorescence intensity in endothelial cell nucleus. These images are representative of five different fields. The results are expressed as the mean \pm S.E.M. from at least five different fields per group from two different experiments. Statistically significant differences $(P<0.05)$ between the control and pRBC groups are indicated by + , and significant differences between pRBCs and pRBCs cultured with t.End.1 pretreated with artesunate are indicated by $*$.

endothelial cells and observed that the pretreatment of endothelial cells with artesunate and further stimulation with TNF- $\alpha$ led to a substantial inhibition of the RBC adhesion to the endothelial cells $(>60 \%$ ) (Figure $4(\mathrm{~d})$ ). Of note, treatment with $300 \mathrm{ng} / \mathrm{mL}$ artesunate was not toxic to the vascular endothelial cell line tEnd.1 (99\% viability).

3.5. NF- $\kappa B$ Nuclear Translocation in Artesunate Pretreated Endothelial Cells Activated by P. berghei-Infected Erythrocytes. RBCs recovered from uninfected mice were not able to induce NF- $\kappa \mathrm{B}$ nuclear translocation in endothelial cells. On the other hand, pRBC activated endothelial cells, as shown by an increased fluorescence in the endothelial nuclei (Figure 5). In contrast, pretreatment with artesunate impaired the nuclear translocation of $\mathrm{NF}-\kappa \mathrm{B}$ in the endothelial cells activated by $P$. berghei-infected erythrocytes.

\section{Discussion}

Artemisinin derivatives are the most important antimalarial treatment available. The mechanism of action of these drugs depends on the alkylation of plasmodium-specific proteins, which prevents the formation of hemozoin and consequently causes the release of free iron that is toxic to the parasite [26]; however the literature has shown that artesunate also presents immunomodulatory effects in mammalian cells $[10,11,27,28]$. Of note, few studies have addressed the effect of artesunate in the murine malaria model and its effect on host immune response. Recently, it was described 
for the first time the efficacy of artesunate in rescuing mice during severe malaria associated with the decrease in leukocyte accumulation in the brain. Herein, we proposed an artesunate mechanism to modulate endothelial cells activation and avoiding the microvascular congestion.

We observed that $24 \mathrm{~h}$ after treatment with artesunate, the parasitemia levels and the symptoms of cerebral malaria were reduced, which are in accordance with results described by Clemmer et al. [15]. Such results are also in agreement with Baptista et al. [29] and Amante et al. [30] who recently demonstrated that during experimental cerebral malaria, increased levels of parasitemia are crucial for clinical symptoms, BBB breakdown, and leukocyte sequestration in the brain microvasculature [31]. Furthermore, we observed a significant decrease in pulmonary edema, splenomegaly, and BBB breakdown during murine severe malaria $12 \mathrm{~h}$ after the administration of a single dose of artesunate, in spite of sustained high parasitemia. Consistently, parasites recovered from artesunate-treated mice were able to infect healthy mice to the same extent as parasites recovered from untreated P. berghei-infected mice. Moreover, we demonstrated that treatment with mefloquine (another antimalarial drug) was neither able to significantly alter the parasitemia levels nor resulted in the reversion of clinical features, such as disruption of $\mathrm{BBB}$ or splenomegaly. These results suggest an auxiliary mechanism of action of artesunate that would explain its early effect during severe malaria.

Artesunate and artemisinin derivatives have activities demonstrated in different pathologies, such as microbial infections, tumor growth, and inflammatory diseases $[3,4,8$, $32,33]$. In vitro studies demonstrated that artesunate treatment impaired the proliferation of phytohemagglutininstimulated peripheral blood mononuclear cells [7] and decreased the neutrophil capacity to phagocytose Escherichia coli in vitro [32]. Moreover, Mirshafiey and coworkers [5] showed a reduction in paw edema and the infiltration of inflammatory cells in the knee joints of artesunate-treated rats with rheumatoid arthritis.

TNF- $\alpha$ is well described as an important cytokine involved in systemic diseases, such as rheumatoid arthritis, septic shock and severe malaria BBB breakdown. In accordance, we observed that treatment with artesunate led to a significant inhibition of TNF- $\alpha$ production in endotoxemic shock assays and in the brain tissue of $P$. berghei-infected mice suggesting that artesunate exhibits an immunomodulatory effect.

To further investigate a putative cell target to artesunate activity, we evaluated the in vitro effect of artesunate on leukocytes and endothelial cells activation after stimulation with pRBCs. The increased expression of adhesion molecules, such as LFA-1 [34] and ICAM-1 [35], is well described during severe malaria. Interestingly, pretreatment with artesunate did not modulate the expression of LFA1 in pRBC-stimulated splenocytes in vitro and, conversely significantly inhibited ICAM-1 expression in pRBC-stimulated endothelial cells. Moreover, RBCs failed to adhere to endothelial cells pretreated with artesunate and stimulated with TNF- $\alpha$, suggesting a direct effect of this drug on endothelial cell activation in a mechanism independent of the parasite. It has already been reported that pRBCs are able to adhere to endothelial cells $[36,37]$, and our results showed that pretreatment with artesunate is also able to inhibit this phenomenon independent of parasite killing.

It is known that ICAM-1, but not LFA-1, expression [38] depends on NF- $\kappa$ B nuclear translocation $[39,40]$, which can be triggered by TNF- $\alpha$ or pRBC. Accordingly, our results demonstrate that artesunate inhibited the NF- $\kappa \mathrm{B}$ pathway in endothelial cells stimulated with pRBCs. Studies have already demonstrated that artemisinin exhibits the ability inhibit the PI3K/Akt signaling pathway and the translocation of $\mathrm{NF}-\kappa \mathrm{B}$ to the nucleus of TNF- $\alpha$-stimulated cells, thereby diminishing the production of pro-inflammatory cytokines $[9,41]$. Compelling evidence has demonstrated that other sesquiterpene lactones similar to artesunate can inhibit NF- $\kappa$ B activation and TNF- $\alpha$ production [42]. In fact, sesquiterpene lactones alkylate the p65 subunit of $\mathrm{NF}-\kappa \mathrm{B}$, which prevents its binding to DNA [43] and may be a possible mechanism by which artesunate exerts its immunomodulatory activity.

Indeed, study of the anti-inflammatory property of artesunate during Plasmodium infection are quite a challenge; however the sum of evidences concerning its antiinflammatory effect in several models [3, 4, 8, 32, 33] and further experiments in vitro and ex vivo with Plasmodium sp.-activated leukocytes and endothelial cells would provide more details of artesunate's effects on inflammatory response during malaria infection. Together, our results suggest that artesunate, in addition to its antimalarial properties, would exert a protective effect against severe malaria via its immunomodulatory properties by inhibiting NF- $\kappa \mathrm{B}$ nuclear translocation and the subsequent expression of ICAM- 1 .

\section{Acknowledgments}

The authors thank Dr. Carmen Penido of Laboratório de Farmacologia Aplicada-Farmanguinhos FIOCRUZ, for her critical reading of the manuscript. Fausto Ferraris is a Ph.D. student of the Post-Graduation Program in Cellular and Molecular Biology of Instituto Oswaldo Cruz and a fellow of Conselho Nacional de Desenvolvimento Científico e Tecnológico (CNPq). This work was supported by grants from $\mathrm{CNPq}$, Fundação Carlos Chagas Filho de Amparo à Pesquisa do Estado do Rio de Janeiro (FAPERJ), CAPES, and Fundação Oswaldo Cruz (FIOCRUZ).

\section{References}

[1] C. J. Woodrow, R. K. Haynes, and S. Krishna, "Artemisinins," Postgraduate Medical Journal, vol. 81, no. 952, pp. 71-78, 2005.

[2] R. J. Maude, C. J. Woodrow, and L. J. White, "Artemisinin antimalarials: preserving the "magic bullet"," Drug Development Research, vol. 71, no. 1, pp. 12-19, 2010.

[3] T. Efferth, H. Dunstan, A. Sauerbrey, H. Miyachi, and C. R. Chitambar, "The anti-malarial artesunate is also active against cancer," International Journal of Oncology, vol. 18, no. 4, pp. 767-773, 2001. 
[4] S. J. F. Kaptein, T. Efferth, M. Leis et al., "The anti-malaria drug artesunate inhibits replication of cytomegalovirus in vitro and in vivo," Antiviral Research, vol. 69, no. 2, pp. 60-69, 2006.

[5] A. Mirshafiey, F. Saadat, M. Attar, R. Di Paola, R. Sedaghat, and S. Cuzzocrea, "Design of a new line in treatment of experimental rheumatoid arthritis by artesunate," Immunopharmacology and Immunotoxicology, vol. 28, no. 3, pp. 397-410, 2006.

[6] A. F. Tawfik, S. J. Bishop, A. Ayalp, and F. S. El-Feraly, "Effects of artemisinin, dihydroartemisinin and arteether on immune responses of normal mice," International Journal of Immunopharmacology, vol. 12, no. 4, pp. 385-389, 1990.

[7] P. Veerasubramanian, P. Gosi, C. Limsomwong, and D. S. Walsh, "Artesunate and a major metabolite, dihydroartemisinin, diminish MITOGEN-induced lymphocyte proliferation and activation," Southeast Asian Journal of Tropical Medicine and Public Health, vol. 37, no. 5, pp. 838-847, 2006.

[8] J. Wang, H. Zhou, J. Zheng et al., "The antimalarial artemisinin synergizes with antibiotics to protect against lethal live Eschenchia coli challenge by decreasing proinflammatory cytokine release," Antimicrobial Agents and Chemotherapy, vol. 50, no. 7, pp. 2420-2427, 2006.

[9] H. Xu, Y. He, X. Yang et al., "Anti-malarial agent artesunate inhibits TNF- $\alpha$-induced production of proinflammatory cytokines via inhibition of NF- $\kappa$ B and PI3 kinase/Akt signal pathway in human rheumatoid arthritis fibroblast-like synoviocytes," Rheumatology, vol. 46, no. 6, pp. 920-926, 2007.

[10] B. Li, J. Li, X. Pan et al., "Artesunate protects sepsis model mice challenged with Staphylococcus aureus by decreasing TNF$\alpha$ release via inhibition TLR2 and Nod 2 mRNA expressions and transcription factor NF- $\kappa \mathrm{B}$ activation," International Immunopharmacology, vol. 10, no. 3, pp. 344-350, 2010.

[11] C. Cheng, W. E. Ho, F. Y. Goh et al., "Anti-malarial drug artesunate attenuates experimental allergic asthma via inhibition of the phosphoinositide 3-kinase/Akt pathway," PLoS ONE, vol. 6, no. 6, Article ID e20932, 2011.

[12] H. C. van der Heyde, J. Nolan, V. Combes, I. Gramaglia, and G. E. Grau, "A unified hypothesis for the genesis of cerebral malaria: sequestration, inflammation and hemostasis leading to microcirculatory dysfunction," Trends in Parasitology, vol. 22, no. 11, pp. 503-508, 2006.

[13] J. B. de Souza, J. C. R. Hafalla, E. M. Riley, and K. N. Couper, "Cerebral malaria: why experimental murine models are required to understand the pathogenesis of disease," Parasitology, vol. 137, no. 5, pp. 755-772, 2010.

[14] D. A. Fidock, P. J. Rosenthal, S. L. Croft, R. Brun, and S. Nwaka, "Antimalarial drug discovery: efficacy models for compound screening," Nature Reviews Drug Discovery, vol. 3, no. 6, pp. 509-520, 2004.

[15] L. Clemmer, Y. C. Martins, G. M. Zanini, J. A. Frangos, and L. J. M. Carvalho, "Artemether and artesunate show the highest efficacies in rescuing mice with late-stage cerebral malaria and rapidly decrease leukocyte accumulation in the brain," Antimicrobial Agents and Chemotherapy, vol. 55, no. 4, pp. 1383-1390, 2011.

[16] P. R. Bauer, H. C. van der Heyde, G. Sun, R. D. Specian, and D. N. Granger, "Regulation of endothelial cell adhesion molecule expression in an experimental model of cerebral malaria," Microcirculation, vol. 9, no. 6, pp. 463-470, 2002.

[17] M. S. Desruisseaux, F. S. Machado, L. M. Weiss, H. B. Tanowitz, and L. M. Golightly, "Cerebral malaria: a vasculopathy," American Journal of Pathology, vol. 176, no. 3, pp. 10751078, 2010.
[18] C. J. Janse, A. P. Waters, J. Kos, and C. B. Lugt, "Comparison of in vivo and in vitro antimalarial activity of artemisinin, dihydroartemisinin and sodium artesunate in the Plasmodium berghei-rodent model," International Journal for Parasitology, vol. 24, no. 4, pp. 589-594, 1994.

[19] P. J. de Vries and T. K. Dien, "Clinical pharmacology and therapeutic potential of artemisinin and its derivatives in the treatment of malaria," Drugs, vol. 52, no. 6, pp. 818-836, 1996.

[20] H. C. van der Heyde, P. Bauer, G. Sun et al., "Assessing vascular permeability during experimental cerebral malaria by a radiolabeled monoclonal antibody technique," Infection and Immunity, vol. 69, no. 5, pp. 3460-3465, 2001.

[21] A. Pamplona, A. Ferreira, J. Balla et al., "Heme oxygenase-1 and carbon monoxide suppress the pathogenesis of experimental cerebral malaria," Nature Medicine, vol. 13, no. 6, pp. 703-710, 2007.

[22] E. Roffê, A. A. Silva, A. P. M. P. Marino, P. V. A. dos Santos, and J. Lannes-Vieira, "Essential role of VLA-4/VCAM1 pathway in the establishment of $\mathrm{CD}^{+} \mathrm{T}$-cell-mediated Trypanosoma cruzi-elicited meningoencephalitis," Journal of Neuroimmunology, vol. 142, no. 1-2, pp. 17-30, 2003.

[23] B. T. Walther, R. Ohman, and S. Roseman, "A quantitative assay for intercellular adhesion," Proceedings of the National Academy of Sciences of the United States of America, vol. 70, no. 5, pp. 1569-1573, 1973.

[24] M. C. de Assis, M. C. Plotkowski, I. M. Fierro, C. BarjaFidalgo, and M. S. de Freitas, "Expression of inducible nitric oxide synthase in human umbilical vein endothelial cells during primary culture," Nitric Oxide, vol. 7, no. 4, pp. 254261, 2002.

[25] N. K. Viebig, U. Wulbrand, R. Förster, K. T. Andrews, M. Lanzer, and P. A. Knolle, "Direct activation of human endothelial cells by Plasmodium falciparum-infected erythrocytes," Infection and Immunity, vol. 73, no. 6, pp. 3271-3277, 2005.

[26] S. Kamchonwongpaisan and S. R. Meshnick, "The mode of action of the antimalarial artemisinin and its derivatives," General Pharmacology, vol. 27, no. 4, pp. 587-592, 1996.

[27] W. D. Li, Y. J. Dong, Y. Y. Tu, and Z. B. Lin, "Dihydroarteannuin ameliorates lupus symptom of BXSB mice by inhibiting production of TNF- $\alpha$ and blocking the signaling pathway NF$\kappa \mathrm{B}$ translocation," International Immunopharmacology, vol. 6, no. 8, pp. 1243-1250, 2006.

[28] B. Li, R. Zhang, J. Li et al., "Antimalarial artesunate protects sepsis model mice against heat-killed Escherichia coli challenge by decreasing TLR4, TLR9 mRNA expressions and transcription factor NF- $\kappa$ B activation," International Immunopharmacology, vol. 8, no. 3, pp. 379-389, 2008.

[29] F. G. Baptista, A. Pamplona, A. C. Pena, M. M. Mota, S. Pied, and A. M. Vigário, "Accumulation of Plasmodium bergheiinfected red blood cells in the brain is crucial for the development of cerebral malaria in mice," Infection and Immunity, vol. 78, no. 9, pp. 4033-4039, 2010.

[30] F. H. Amante, A. Haque, A. C. Stanley et al., "Immunemediated mechanisms of parasite tissue sequestration during experimental cerebral malaria," Journal of Immunology, vol. 185, no. 6, pp. 3632-3642, 2010.

[31] P. Cabrales, G. M. Zanini, D. Meays, J. A. Frangos, and L. J. M. Carvalho, "Nitric oxide protection against murine cerebral malaria is associated with improved cerebral microcirculatory physiology," Journal of Infectious Diseases, vol. 203, no. 10, pp. 1454-1463, 2011.

[32] M. E. Sarciron, C. Saccharin, A. F. Petavy, and F. Peyron, "Effects of artesunate, dihydroartemisinin, and an artesunatedihydroartemisinin combination against Toxoplasma gondii," 
American Journal of Tropical Medicine and Hygiene, vol. 62, no. 1, pp. 73-76, 2000.

[33] H. H. Chen, H. J. Zhou, G. D. Wu, and X. E. Lou, "Inhibitory effects of artesunate on angiogenesis and on expressions of vascular endothelial growth factor and VEGF receptor KDR/flk-1," Pharmacology, vol. 71, no. 1, pp. 1-9, 2004.

[34] A. Ohayon, J. Golenser, R. Sinay et al., "Protein kinase C $\theta$ deficiency increases resistance of C57BL/6J mice to Plasmodium berghei infection-induced cerebral malaria," Infection and Immunity, vol. 78, no. 10, pp. 4195-4205, 2010.

[35] N. Favre, C. Da Laperousaz, B. Ryffel et al., "Role of ICAM1 (CD54) in the development of murine cerebral malaria," Microbes and Infection, vol. 1, no. 12, pp. 961-968, 1999.

[36] L. Joergensen, D. C. Bengtsson, A. Bengtsson et al., "Surface co-expression of two different PfEMP1 antigens on single Plasmodium falciparum-infected erythrocytes facilitates binding to ICAM1 and PECAM1," PLoS Pathogens, vol. 6, no. 9, Article ID e01083, 2010.

[37] D. A. Fedosov, B. Caswell, S. Suresh, and G. E. Karniadakis, "Quantifying the biophysical characteristics of Plasmodiumfalciparum- parasitized red blood cells in microcirculation," Proceedings of the National Academy of Sciences of the United States of America, vol. 108, no. 1, pp. 35-39, 2011.

[38] M. Semmrich, A. Smith, C. Feterowski et al., "Importance of integrin LFA-1 deactivation for the generation of immune responses," Journal of Experimental Medicine, vol. 201, no. 12, pp. 1987-1998, 2005.

[39] A. K. Tripathi, D. J. Sullivan, and M. F. Stins, "Plasmodium falciparum-infected erythrocytes increase intercellular adhesion molecule 1 expression on brain endothelium through NF- $\kappa \mathrm{B}$," Infection and Immunity, vol. 74, no. 6, pp. 3262-3270, 2006.

[40] A. K. Tripathi, W. Sha, V. Shulaev, M. F. Stins, and D. J. Sullivan Jr., "Plasmodium falciparum-infected erythrocytes induce NF- $\kappa \mathrm{B}$ regulated inflammatory pathways in human cerebral endothelium," Blood, vol. 114, no. 19, pp. 4243-4252, 2009.

[41] E. Aldieri, D. Atragene, L. Bergandi et al., "Artemisinin inhibits inducible nitric oxide synthase and nuclear factor NF- $\kappa \mathrm{B}$ activation," FEBS Letters, vol. 552, no. 2-3, pp. 141-144, 2003.

[42] S. P. Hehner, M. Heinrich, P. M. Bork et al., "Sesquiterpene lactones specifically inhibit activation of NF- $\kappa \mathrm{B}$ by preventing the degradation of $\mathrm{I} \kappa \mathrm{B}-\alpha$ and $\mathrm{I} \kappa \mathrm{B}-\beta$," The Journal of Biological Chemistry, vol. 273, no. 3, pp. 1288-1297, 1998.

[43] G. Ly, A. Knorre, T. J. Schmidt, H. L. Pahl, and I. Merfort, "The anti-inflammatory sesquiterpene lactone helenalin inhibits the transcription factor NF- $\kappa \mathrm{B}$ by directly targeting $\mathrm{p} 65$," The Journal of Biological Chemistry, vol. 273, no. 50, pp. 33508 33516, 1998. 


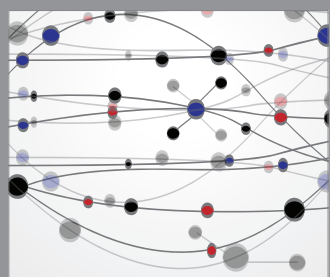

The Scientific World Journal
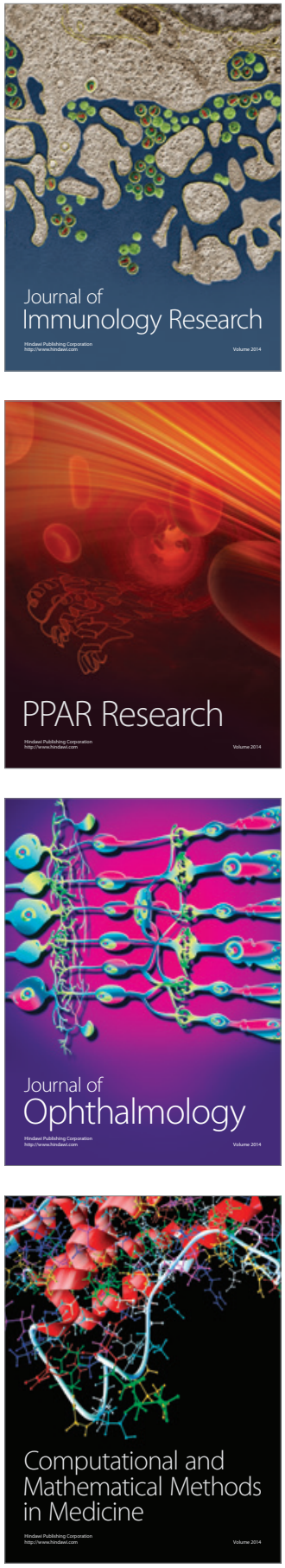

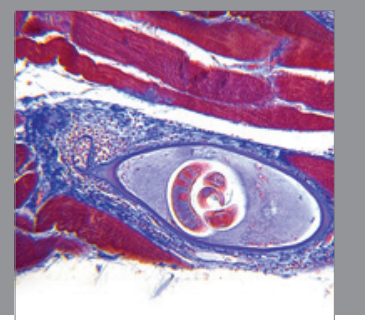

Gastroenterology

Research and Practice
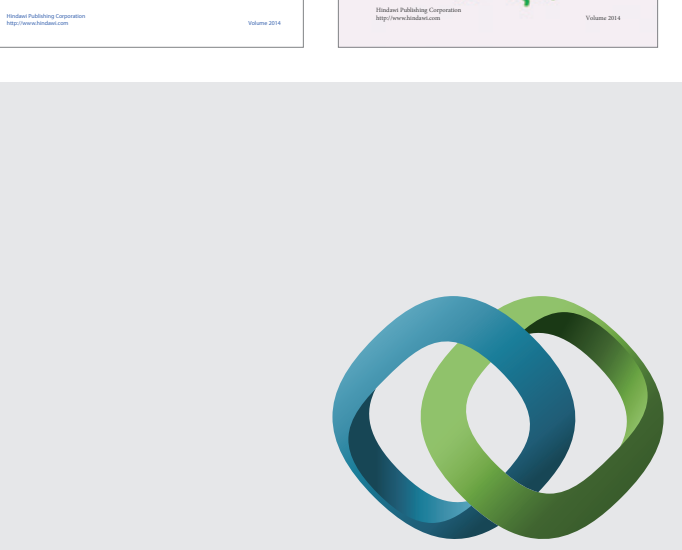

\section{Hindawi}

Submit your manuscripts at

http://www.hindawi.com
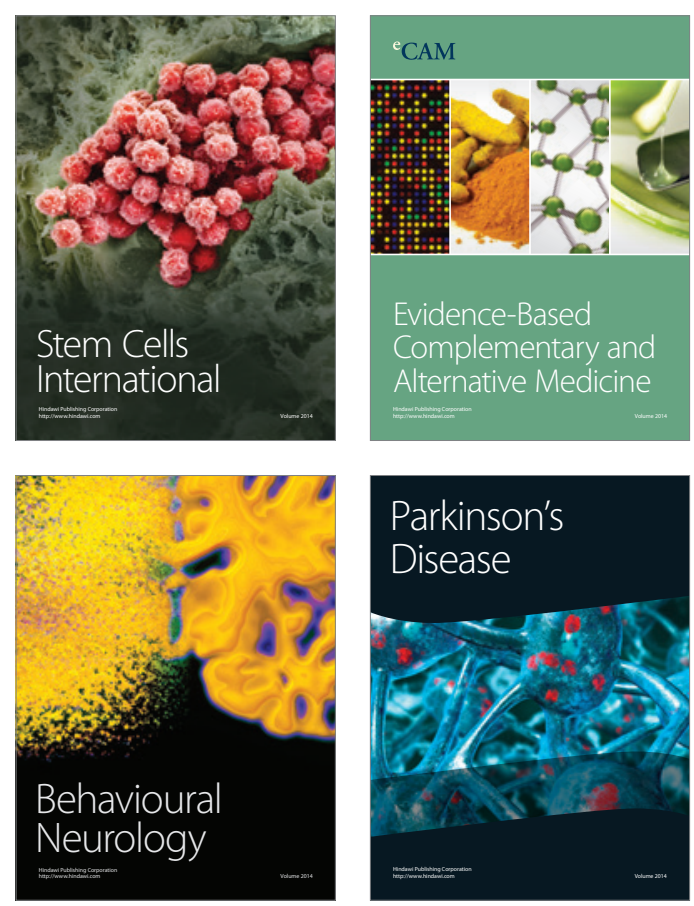

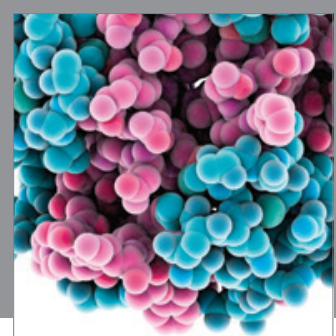

Journal of
Diabetes Research

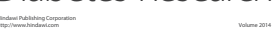

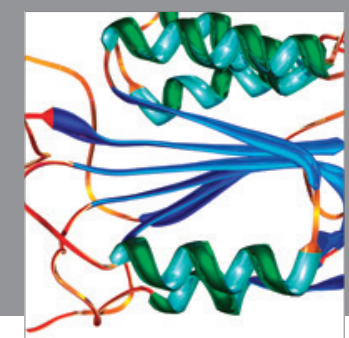

Disease Markers
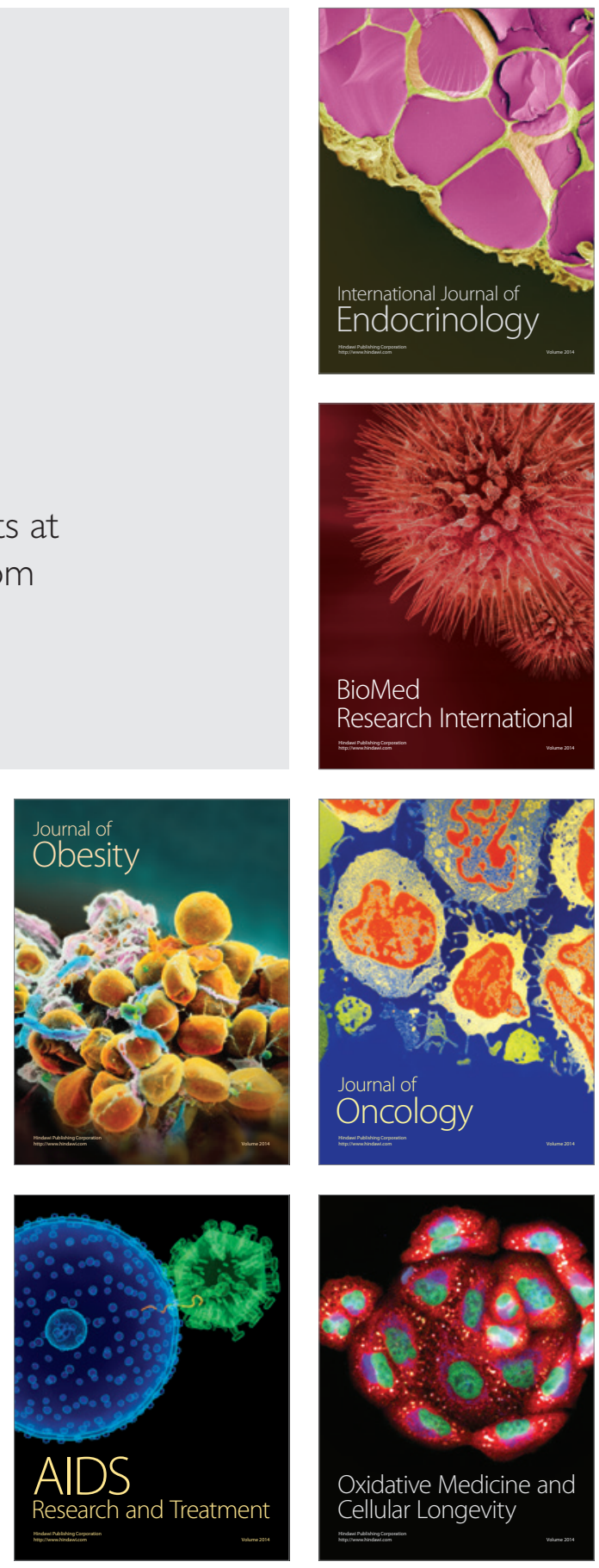